Estonian Journal of Archaeology, 2005, 9, 1, 73-81

\title{
Ülle Sillasoo
}

\section{MIS SAAB ARHEOBOTAANIKAST EESTIS?}

\begin{abstract}
Arheobotaanika on Eestis vähetuntud teadusala, mida siinsetes ülikoolides ei õpetata ning millega pidevalt tegelevaid ja tegelnud inimeste kokkulugemiseks piisab ühe käe sõrmedest. Samas viitab nii arheoloogiliste kaevamiste kui ka võetud pinnaseproovide arv teatud vajadusele ja võimalusele selles valdkonnas pisut enam ära teha. Arheobotaanilised leiud on materiaalse kultuuri uurimise üks allikatest. Väljakaevamised on üksnes andmete kogumiseks ja baasiks järgnevale teadustööle. Arheobotaanika on Eestis kriisiseisus, kuna väljaõppinud spetsialistidele ei leidu erialast tööd. Ühe põhjusena näeb autor riiklikult finantseeritava linnaarheoloogia ja materiaalse kultuuri uurimiskeskuse puudumist. Lahenduseks oleks koostöö arendamine välismaa kolleegidega, mis ei välistaks koostööd kodumaiste arheoloogide, ajaloolaste ja loodusteaduslikke meetodeid kasutavate spetsialistide vahel.
\end{abstract}

Archaeobotany is a discipline little known in Estonia. It is not taught at local universities, and the specialists who work or have worked in this area could be counted on one hand only. At the same time, the increasing number of archaeological investigations and samples that have been taken for archaeobotanical research refer to a certain necessity and opportunities to go further. Archaeobotanical finds are sources for the history of material culture. Excavations are just one part of the investigation meant for collecting data on which further research work is based. Estonian archaeobotany could be considered in crisis because graduated specialists are unemployed. As one of the reasons the author sees the lack of a state financed research centre of medieval town archaeology and material culture. As a solution the author proposes collaboration with foreign colleagues, which at the same time would not exclude collaboration between domestic archaeologists, historians and specialists who use natural scientific methods in archaeology.

Ülle Sillasoo, Institute of Ecology at Tallinn University (Tallinna Ülikooli Ökoloogia Instituudi maastikuökoloogia osakond), Kevade 2, 10137 Tallinn, Eesti; ulle.sillasoo@eco.edu.ee

\section{Sissejuhatus}

Arheoloogiliste kaevamistega seonduvad enamasti ehitiste ja konstruktsioonide jäänused, esemelised leiud ja kaevandi stratigraafia. Vähem räägitakse nn arheoloogilisest maatriksist, mis neid konstruktsioone ja esemeid ümbritseb või täidab. See pealtnäha ilmetu surnud pinnas sisaldab möödunud aegadest säilinud ja kuhjunud elutegevuse jäänuseid. Selles arheoloogilises maatriksis võib eristada anorgaanilist osa, kuhu kuuluvad pinnase looduslikud mineraalsed koostisosad, 
ja orgaanilist osa, mille moodustavad looduslikud ja antropogeensed taime- ja loomajäänused. Aine tasandist kõneldes sisaldab pinnas looduslikke ja inimtegevuse tagajärjel tekkinud keemilisi ühendeid. Kaasaja arheoloogias kasutatakse mitmesuguseid loodusteaduslikke meetodeid, selgitamaks, millist lisateavet see maatriks vastava paiga kohta sisaldab. Artikkel annab ülevaate ühe sellesse valdkonda kuuluva eriala - arheobotaanika - olemusest, allikatest ja üldistest uurimisvaldkondadest ja käekäigust Eestis ning püüab leida vastuseid tekkinud küsimustele, miks ei saa teha Eestis arheobotaanilist teaduslikku tööd ning mida teha selleks, et eriharidusega keskkonnaarheoloogid ei peaks otsima tööd muudest valdkondadest või teadusest hoopiski loobuma. Käesolev ülevaade lähtub arheobotaaniku ja keskaja materiaalse kultuuri uurija vaatevinklist.

\section{Mis on arheobotaanika?}

Arheobotaanika on kitsas tähenduses arheoloogiliste taimejäänuste uurimine. Paralleelselt arheobotaanikaga kasutatakse paleo-etnobotaanika mõistet, mille tuletas 1950. aastatel taani teadlane Hans Helbaek (1955), eristamaks vastavat uurimisvaldkonda klassikalisest loodust uurivast paleobotaanikast. Arheo- ehk paleo-etnobotaanika keskendub inimtegevuse ja kultuuri uurimisele, seostades looduslikust keskkonnast pärit leide taimede kasutuse ja sihipärase ümberpaigutusega peamiselt igapäevaelu ja asustust ümbritseva maastiku kujundamise eesmärgil. Taimed, mida inimesega seotud paikadest leitakse, on suure tõenäosusega täitnud toiduainete, ravimite, toor- ja ehitusmaterjalide ning energiaallikate ülesandeid, samuti rahuldanud inimeste rituaalseid ja esteetilisi vajadusi (vt Willerding 1978; Hall jt 1982; Steuer 1986; Hastorf \& Popper 1988; Greig 1989; Zeist jt 1991; Jacomet \& Kreuz 1998).

Arheobotaanika on seotud paljude inimtegevuse ja materiaalse kultuuri valdkondadega, näiteks põllumajanduse, aianduse, kulinaaria, meditsiini ja kaubavahetusega. Arheoloogilisi taimeleide liigitataksegi nende üldise ainelise funktsionaalsuse ja kontekstuaalsel baasil, kuna mitmesugused ideoloogilised aspektid ei ole selle uurimismeetodiga enamasti haaratavad. Samas võisid ühed ja samad taimed täita mitmeid majanduslikke, kultuurilisi ning võimalik, et ka poliitilisi rolle, mis selgub alles erinevat tüüpi materjale ja dokumente uurides. Arheobotaanika all võib laias tähenduses mõista ka antropogeensete taimede ajaloo ja osa kultuuris uurimist, mille allikateks on peale arheobotaaniliste leidude veel vihjed ja viited kirjalikes ning kujutised pildilistes materjalides ja mõnikord suuline pärimus niivõrd, kuivõrd see ei tulene kirjasõnast või piltidest.

Arheobotaanika allikate olemasolu ja valik sõltub sellest kultuuripärandi osast, mis on omandanud materiaalse kuju. Meie teadmised on määratud sellega, millisena ja kui suures mahus see pärand on säilinud ja meieni jõudnud. Nagu ikka, luuakse, kas teadlikult või ebateadlikult, kultuuripärandi säilimiseks jõukamates kihtides enamasti paremad tingimused kui vaesemates ning sellega seoses kajastab suurem osa allikmaterjalidest kõrgema sotsiaalse ja materiaalse positsiooniga 
inimeste elu. Arheoloogiliste taimejäänuste säilimisel on tähtsad nii säilimistingimused pinnases, taimeosade erinev vastupidavus, nende erinevad töötlemisning kasutusviisid kui ka vastavate taimede ohtrus, kasutatud taimeosade spetsiifilisus ja tarbitud kogused. Taimejäänuseid leitakse sageli prahi kontekstis, mistõttu nendel kui allikatel ei ole ühiskonnas nii suurt materiaalset väärtust kui kirjalikel ja pildilistel. Kultuuriajaloo seisukohalt on aga taimede arheoloogilised leiud sama tähtsad kui taimede jäädvustused sõnas ja pildis.

Kuna arheoloogilised taimeleiud „ei räägi“, on paralleelselt arheoloogilise uurimistööga vajalik tegelda ka kirjalike ja pildiliste allikate uurimisega, eriti mis puudutab keskaja ja varase uusaja perioode, selgitamaks põhjalikumalt vastavaid kultuurilisi kontekste ja vältimaks ajalooliste leidude tõlgendamist hilisematest kultuurilistest kontekstidest lähtuvalt. Kirjalikud materjalid aitavad vastata küsimustele „kuidas?“ ja „miks?“ ning võimaldavad uurida taimede kui sümbolite rolle, kuid samas nõuavad erilist tähelepanu ja lähenemist nimede tõlgendamise seisukohalt, sest terminoloogia, mida seal kasutatakse, pole taimede liigispetsiifiline. Ka piltidel kujutatud taimed, mis võivad viidata teatud taimede olemasolule, kasutusele ja rollile igapäevaelus, ei ole mineviku üksühene peegeldus, vaid pigem üldistuste, kogemuste, traditsioonide ja sümbolite kogumid, mille tähendus muutub mõistetavamaks kirjanduslike tekstide, ajalooliste rituaalide, ebausu, traditsioonide ja teaduse arengu taustal (Sillasoo 2003a; 2003b). Seega ei saa näiteks keskajale spetsialiseerunud arheobotaanik tegelda vaid arheoloogiliste taimeleidude uurimisega, vaid peab kontekstide selgitamisel kasutama kõiki olemasolevaid allikaid. Samas muutuvad need allikad arheobotaanikutele ja ajalooliste taimede uurijatele kättesaadavaks üksnes arheoloogide, ajaloolaste ja kunstiajaloolaste vahendusel, mis teeb selle töö mitmekordselt interdistsiplinaarseks.

Arheobotaanika on ühenduslüli humanitaar- ja loodusteaduste vahel, saades ühelt allikad ja teiselt uurimisobjekti. Kahjuks pööratakse kaasaja botaanikas aja ja kultuuri dimensioonile vähe tähelepanu ja nii ei arvata meil arheobotaanikat loodusteaduste valdkonda kuuluvaks. Ka taimkatte ajalugu õpetatakse Eesti ülikoolides minimaalselt või üldsegi mitte ning kaasaegsed botaanilised uuringud ei näi vajavat ajaloolist lähenemist enamaks kui sensatsiooniks. Siiski on igal botaanilisel uuringul peale ruumiliste ka ajalised koordinaadid. Taimkatte kujunemisel ja muutumisel on inimesel ja tema kultuuril oluline tähtsus, mille nüansid avalduvad taimede ajaloo, leviku ja kasutuse uurimisel. Inimene ei saa läbi teda ümbritseva looduseta, mida ta oma kultuuriga mõjutab isegi siis, kui esimese uurimisega tegelevad loodusteadlased ja teisega humanitaarid.

\section{Arheobotaanika uurimisseis Eestis}

Arheobotaanika ajalugu Eestis on lahutamatu siinse arheoloogia ja paleobotaanika ajaloost (vt Laasimer 1965; Jaanits jt 1982; Jaanits 1988; Kungur \& Selirand 1988; Lõugas 1988; Jaanits 1991; Rõuk 1992; Lang 2000; Soon jt 2000). 
Vanimad teadaolevad viited arheobotaanilisele materjalile Eestis pärinevad aastast 1867, kui Tartu ülikool ostis Isamaalise Muististe Keskmuuseumi (Zentralmuseum vaterländischer Alterthümer der Kaiserlichen Universität zu Dorpat) jaoks 32 liigi seemnetest koosneva taimejäänuste kogu. Ometi ei pärinenud need taimejäänused mitte 19. sajandi väljakaevamistelt Eestis, vaid hoopis Robenhauseni vaiehitise väljakaevamistelt Šveitsis (vt AI 2635: 2213). Rahvusvahelises kontekstis toimus see arheobotaanika ajaloo ja arengu esimesel etapil, milleks loetakse aastaid 1865-1947. Euroopa tasandil arvatakse arheobotaanika nurgakiviks taani teadlase Osvald Heeri (1865) publikatsiooni ja nimelt vaiehitistest leitud taimedest (Willerding 1978).

Pikka aega olid arheobotaanilised uuringud Eestis pühendatud ainult muinasaegsetest asulakohtadest ja linnustest leitud söestunud kultuurtaimede määramisele, millega tegelesid mitmed taimede või nende kasvatamisega seotud erialade spetsialistid. 1930. aastatel leitud Saaremaa Asva asulakoha ja Tallinna lähistel Iru linnuse potikildudel uuriti teraviljajäljendeid ja määrati söestunud teravilja, Kuusalu Pajulinna söestunud ladestustes tera- ja kaunvilju (Lõugas 1988; Moora 1939). Seejuures tegeles Iru linnuse söestunud teravilja määramisega Tartu ülikooli põllumajandusosakonna õppejõud Nikolai Rootsi (1888-1974). Esimeseks siinset arheobotaanilist materjali põhjalikumalt uurinud teadlaseks vahetult pärast Teist maailmasõda oli aga läti botaanik Alfred Rasinš (1916-1995). Uurides 1950. aastatest alates muinasaegseid söestunud teravilja ladestusi nii Lätis kui ka naabermaades, tegi ta kindlaks mitmeid varasemaid ja uuemaid teraviljajäljendeid ning -proove, sh Asva, Iru, Kuusalu ja Otepää asulakohtade ja linnuste kaevamistelt. Nende ja tema mitmete teiste teravilja- ja umbrohuleidude baasil tehtud uurimistööd avaldasid märgatavat mõju tolleaegsetele arusaamadele Eesti ja Läti muinasaegsest põllundusest. Rasinš oli teadaolevalt esimene, kes rõhutas, et iga arheoloogiliste kaevamistega tegeleva instituudi juures peaks asuma arheobotaanikalabor (Lõugas 1988). Rasinš polnud tol ajal taas mitte ainus siinsete taimsete makrojäänuste määraja. Taimejäänuste juhuleiud, mis kaevati 1950. aastatel Tartu muinaslinnuse uurimise käigus, määras kindlaks Tartu ülikooli taimefüsioloogia ja geobotaanika osakonna tolleaegne juhataja professor Heigo Miidla (1919-1989) (Trummal 1964). Eesti Põllumajanduse Akadeemia põllumajanduse ja sordiaretuse osakonna juhataja professor Hugo Richard Sutter (1909-1974) määras samal ajal Rõuge muinaslinnuse söestunud teraviljade leiud. Söestunud teravilja Soontaga muinaslinnuse väljakaevamistelt (1966-1971) tegi kindlaks Jaan Lepajõe (1928-1999) Eesti Põllumajanduse Akadeemiast (Tõnisson \& Lepajõe 1978). Eestis ei olnud ühtki arheobotaanikut, kes oleks spetsialiseerunud arheoloogilistelt kaevamistelt leitud taimejäänuste uurimisele. Nii-öelda juhuslikke taimeleide määrasid sageli juhuslikud uurijad, kes piirdusid väljapaistvamate leidude dokumenteerimisega.

1986. aastal loodi Eesti NSV Teaduste Akadeemia Ajaloo Instituudi juurde geoarheoloogia ja muinastehnoloogia labor, kus hakati järjepidevalt läbi viima projekte, mis tegelesid muinasaegse loodusliku keskkonna ja selle muutumisega seotud temaatikaga. Intensiivse ehitustegevuse algus linnades sel perioodil tõi 
endaga kaasa ka keskaja arheoloogia ja taimeleidude uurimise (Tammet 1988). 1988. aastal loodi Eesti Muinsuskaitse Seltsi juurde arheoloogiarühm AGU ning aasta hiljem võeti sinna tööle arheobotaanik, selle artikli autor. Võiks öelda, et 1980. aastate lõpp tähistab süstemaatilise arheobotaanilise uurimistöö algust Eestis. Arheobotaanilisi proove koguti ja määrati peaaegu kõikides keskaegsetes kaevandites, kus leidus vettinud kihte ja söestunud ladestusi hästi säilinud taimejäänustega, näiteks kaevandiprofiilides, jäätmekastides ja muudes ehitusjäänustes. Nendest leidudest on tänaseks tekkinud mahukas andmebaas (Sillasoo 1997). Suurem osa nendest andmetest on teaduslikult läbi töötamata ja publitseerimata, paljudel proovidel puuduvad dateeringud. Peamine põhjus seisneb ilmselt selles, et väljakaevamised linnades on tavaliselt päästekaevamised, mida finantseerib vastavale alale valmiva ehitise tellija, kes on huvitatud tööde kiirest teostamisest, mida märgib lõpparuanne. Väljakaevamiste tulemuste teaduslik läbitöötamine ja publitseerimine pole olnud kohustuslik, mistõttu sõltuvalt töid teostanud arheoloogist võibki materjal jääda avaldamata. Samas on Eesti keskaegsetes linnades läbi viidud arheoloogiliste kaevamiste arv suur ja see suureneb iga aastaga (Trummal 1990; Alttoa \& Tamm 1992; Tamm 1993; Valk 1993; 1995; Metsallik 1995; Pärn \& Tamm 1999; Vissak 1999; Vunk 1999).

Arheobotaanilise materjali poolest on kõige paremini läbi uuritud keskaegne Tartu (Tammet 1988; Abakumova 1990; Abakumova \& Sillasoo 1991; Sillasoo 1995; 1997; 2001; 2002; Hiie 2002). Tartu kaevamiste andmeid on kasutatud diplomi- ja kraadiõppe lõputööde kirjutamiseks Tartu Ülikoolis ja Kesk-Euroopa Ülikoolis Budapestis (Sillasoo 1989; 1996; Uudelt 1991) ja üksikuteks uurimistoetustega rahastatud projektide läbiviimiseks (Sillasoo 1997). Üks viimaseid suuremaid töid oli ETF-i uurimistoetuse ja selle hoidja Jaan Tamme toetusel arheobotaaniliste leidude ja kirjalike viidete põhjal läbi viidud Eesti keskaegseid linnu hõlmanud uurimus, mis käsitleb hansakaubanduse mõju hindamist toitumisele keskaegses Põhja-Euroopas, kaasa arvatud keskaegne Liivimaa (Sillasoo \& Hiie 2003; Sillasoo 2004). Koos leidude süstematiseerimisega käsitlevad need uurimused keskaegse linnaelu ökoloogilisi ja igapäevaeluga seotud aspekte.

\section{Kuhu lähed, eesti arheobotaanika?}

Arheobotaaniline uurimistöö nõuab korraliku tehnikaga laborit ja hulgaliselt aega mikroskoopimiseks ning tulemuste läbitöötamiseks kirjalike allikate ja arheoloogia kontekstis. Sellega ei saa tegelda üksnes avariikaevamiste käigus. Arheobotaanika on ka selline uurimisvaldkond, mis laiemas teaduslikus kontekstis ei kuulu ega hakkagi ilmselt kuuluma prioriteetide hulka. Või kui, siis oleks tegemist pigem moeküsimusega. Praeguse seisuga tundub arheobotaanika olevat Eestis kaduv eriala, sest leidudel põhinevat teaduslikku tööd ei toimu ning selle eriala nn kriitiline mass on liiga väike, et muude erialadega iseseisvalt konkureerida. Uutel teaduslikel publikatsioonidel puudub finantseerija, sest sihtfinantseerimise määrab juba olemasolevate publikatsioonide arv ja kvaliteet. „Võõra“ 
instituudi „võõra“ teema eest vastutaja ei luba enda teema arvel „muude asjadega" tegelda.

Arheobotaanika võiks kuuluda taimkatte, kultuurtaimede ja keskkonnaajaloo õppeprogrammidesse seal, kus neid kursusi läbi viiakse. Arheobotaanika kui eriala ja uurimismeetod võiks kuuluda arheoloogia ja materiaalse kultuuri ning igapäevaelu ajaloo õppeprogrammidesse selleks, et selgitada võimalusi, mida vastav uurimistöö võib avada, ja aspekte, millega tuleks arvestada. Teadustöö seisukohalt on arheobotaanika kaasamine hädavajalik eriti keskaja linnade arheoloogiasse ja keskaja materiaalse kultuuri uurimisse, samuti nagu arheozooloogia ja antropoloogia. Taoline interdistsiplinaarne lähenemine kultuuriajaloo uurimisele ei oleks mitte üksnes soositud, vaid suisa kohustuslik ning annaks suurepäraseid tulemusi, kui leiduks linnaarheolooge, kes paneksid kokku keskaja linnu ja nende materiaalset kultuuri käsitlevaid interdistsiplinaarseid projekte. Ideaalis võiks eesti arheobotaanika kõrvuti väljakaevamiste ja andmete süstematiseerimisega tegelda veel näiteks Eesti ala ning selle keskaegsete linnade taimkatte ja haljastuse, põlluviljade umbrohukoosluste ning põllumajandusajaloo, toitumise ja taimede muude kasutusviisidega seotud küsimuste uurimisega. Seda saab teha aga ainult siis, kui teaduses nii vajalik kriitiline mass või kontekst on olemas ja/või kui koostöö arheoloogide, ajaloolaste, kunstiajaloolaste ja nende uurijate vahel, kes töötavad keskkonnaajaloo erinevate aspektide uurimisega, oleks tõhusam.

\section{Kokkuvõte}

Tänapäeval tehakse pinnase arheobotaanilisi analüüse vaid Ajaloo Instituudi geoarheoloogia ja muinastehnoloogia laboris Tallinnas, kuna nende ja varasemate andmete teaduslik läbitöötamine kuulub asjast huvitatute hobide valdkonda. Ülalkirjutatust johtuvalt ei piirdu arheobotaanika aga mitte üksnes leidude määramisega, eriti mis puudutab keskaja taimeleide. Tööpõld pole üksnes lai, vaid ka huvitav, seda ka laiema publiku vaatevinklist lähtuvalt. Kuigi muinasaegseid taimeleide on Eestis määratud ja uuritud juba möödunud sajandi algusest saadik, on suurem keskaegsete taimeleidude andmekogu, spetsialistid ja mõningane potentsiaal arheobotaanikaga teaduslikult tegelda tekkinud alles hiljuti. Samas on aga kujunenud olukord, kus juhtivate teadusalade nagu botaanika ja arheoloogia võimalused on piiratud, kaasamaks teadusse ja haridusse interdistsiplinaarseid, aeganõudvaid ja produktsioonilt teistele alla jäävaid arheobotaanika teemasid. Interdistsiplinaarsus on spetsialistile mõneti kurnav mitte üksnes vajalike teadmiste rohkuse, vaid ka mittemõistmise ja mitterahastamise suure ohu tõttu. Kuigi tänapäeva teaduspoliitikas seatakse see sageli eesmärgiks, on tegelikus elus interdistsiplinaarselt mõtlevaid teadlasi vähe. Ilmselt ei saa ka väikese Eesti teadus tervikuna paljudel juhtudel selliseid ekstravagantsusi endale lubada ning tõenäoliselt tuleb laienenud Euroopas välisabile igas mõttes rohkem loota. Järjepidevuse ja orienteerituse seisukohalt oleks hea, kui igal maal oma kodumaine spetsialist võtta oleks. 


\section{Kasutatud kirjandus}

Abakumova, M. 1990. Taimseid ja loomseid leide Tartu vanalinnast. - Tartu ja kultuur. Tallinn, $22-30$.

Abakumova, M. \& Sillasoo, Ü. 1991. Taimseid leide arheoloogilistes proovides. Botaanilised uurimused. - Scripta Botanica, 6, 197-215.

Alttoa, K. \& Tamm, J. 1992. A glimpse at research into historic towns in Estonia: Current results and perspectives. - Estonia: Nature, Man and Cultural Heritage. Proceedings of a Round Table held at Tallinn, April 1991 at the Estonian Academy of Sciences. Toim T. Hackens, V. Lang \& U. Miller. (PACT, 37.) Rixensart, 63-76.

Greig, J. 1989. Archaeobotany. Handbooks for Archaeologists. European Science Foundation.

Hall, A. R., Kenward, H. K. \& Keene, D. J. (toim). 1982. Environmental Archaeology in the Urban Context (Research Report, 43). London.

Hastorf, C. A. \& Popper, V. S. (toim). 1988. Current Palaeoethnobotany, Analytical Methods and Cultural Interpretations of Archaeological Plant Remains. The University of Chicago Press. Chicago.

Heer, O. 1865. Die Pflanzen der Pfahlbauten. - Neujahrsblatt der Naturforschenden Gesellschaft Zürich für das Jahr, 1866, 68.

Helbaek, H. 1955. La recherche paletnobotanique. Une science née de la découverte des palafittes. - Sibrium, 2, 225-232.

Hiie, S. 2002. An example from the archaeobotanical investigations of medieval Tartu, Estonia. Abstract. - Nordic Archaeobotany - NAG 2000 in Umeå. Toim K. Viklund. (Archaeology and Environment, 15.) University of Umeå, 203.

Jaanits, L. 1988. Eesti sooarheoloogiast. - Eesti sood. Toim U. Valk. Tallinn, 217-221.

Jaanits, L. 1991. Nõukogude Eesti arheoloogia Tartu-periood. - Arheoloogiline kogumik. Muinasaja teadus, I. Toim L. Jaanits \& V. Lang. Tallinn, 20-44.

Jaanits, L., Laul, S., Lõugas, V. \& Tõnisson, E. 1982. Eesti esiajalugu. Tallinn.

Jacomet, S. \& Kreuz, A. 1998. Archäobotanik. Verlag Eugen Ulmer. Stuttgart.

Kungur, V. \& Selirand, J. (toim). 1988. Nõukogude Eesti arheoloogia bibliograafiline nimestik 1940-1985, 1. kd (1-884); Nõukogude Eesti arheoloogia bibliograafiline nimestik 1940-1982, 2. kd (885-1800). Tallinn.

Laasimer, L. 1965. Eesti NSV floora ja vegetatsiooni koosseis ja kujunemine. - Eesti NSV taimkate. Tallinn, 41-47.

Lang, V. 2000. Eesti arheoloogia 20. sajandi teisel poolel. - EAA, 4: 1, 72-77.

Lõugas, V. 1988. Loodusteaduslike meetodite kasutamisest Eesti arheoloogias. - Loodusteaduslikke meetodeid Eesti arheoloogias. Artiklite kogumik. Toim A.-M. Rõuk \& J. Selirand. Tallinn, 9-25.

Metsallik, R. 1995. Tartu arheoloogilisest uurimisest. - Tartu arheoloogiast ja vanemast ehitusloost. Toim H. Valk. (TÜAKT, 8.) Tartu, 15-35.

Moora, H. (toim). 1939. Muistse Eesti linnused. 1936.-1938. a. uurimiste tulemused. Tartu.

Pärn, A. \& Tamm, J. 1999. Estonia. - Report on the Situation of Urban Archaeology in Europe. Strasbourg, 73-79.

Rõuk, A.-M. 1992. Interdisciplinary research on environmental history and archaeology. - Estonia: Nature, Man and Cultural Heritage. Proceedings of a Round Table held at Tallinn, April 1991 at the Estonian Academy of Sciences. Toim T. Hackens, V. Lang \& U. Miller. (PACT, 37.) Rixensart, $51-61$.

Sillasoo, Ü. 1989. Taimsed leiud Tartu vanalinna arheoloogilistes proovides. Diplomitöö. Tartu Ülikooli botaanika õppetool.

Sillasoo, Ü. 1995. Tartu 14.-15. sajandi jäätmekastide taimeleidudest. - Tartu arheoloogiast ja vanemast ehitusloost. Toim H. Valk. (TÜAKT, 8.) Tartu, 115-28. 
Sillasoo, Ü. 1996. Daily Food and Meal Traditions in Late Medieval Tartu, Estonia (14th and 15th centuries). M. A. Thesis in Medieval Studies. Central European University. Budapest.

Sillasoo, Ü. 1997. Eesti keskaegsete linnade ja nende lähiümbruse arheobotaanilisest uurimisest 1989-1996. - Arheoloogilisi uurimusi. Toim H. Valk. (TÜAKT, 9.) Tartu, 109-119.

Sillasoo, Ü. 2001. Ecology and food consumption of Late Medieval Tartu, Estonia (14th-15th centuries). - Medium Aevum Quotidianum, 44, 6-40.

Sillasoo, Ü. 2002. Gardens and garden products in medieval Tartu. - Nordic Archaeobotany NAG 2000 in Umeå. Toim K. Viklund. (Archaeology and Environment, 15.) University of Umeå, $181-192$.

Sillasoo, Ü. 2003a. Plant Depictions in Late Medieval Religious Art in Southern Central Europe. $\mathrm{Ph}$. D. Thesis in Medieval Studies. Central European University. Budapest.

Sillasoo, Ü. 2003b. Plant depictions in medieval religious art. - People and Nature in Historical Perspective. Toim J. Laszlovszky \& P. Szabó. Central European University \& Archaeolingua. Budapest, 377-393.

Sillasoo, Ü. \& Hiie, S. 2003. Archaeobotanical approach to Hanseatic food investigation in Estonia. Esitatud juunis 2003 Hansa-Network-projekti monograafia toimetajale dr Sabine Kargile Taani Rahvusmuuseumis.

Sillasoo, Ü. 2004. Defining food boundaries on the basis of late medieval urban archaeobotanical material. - Esitatud märtsis 2004 Euroopa Toiduajaloo Instituudi ajakirjale Food and History (Brepols Publishers).

Soon, L., Luik, H. \& Tamla, Ü. (toim). 2000. Eesti arheoloogia bibliograafia 1986-1996. Tallinn.

Steuer, H. (toim). 1986. Zur Lebensweise in der Stadt um 1200: Ergebnisse der MittelalterArchäologie (Zeitschrift für Archäologie des Mittelalters, Beiheft 4).

Tamm, J. 1993. Of the older settlement of Tallinn. - Castella Maris Baltici, 1. Toim K. Drake. Stockholm, 205-211.

Tammet, M. 1988. Tartu keskaegsete jäätmekastide karpoloogilise analüüsi tulemusi. - Loodusteaduslikke meetodeid Eesti arheoloogias. Artiklite kogumik. Toim A.-M. Rõuk \& J. Selirand. Tallinn, 97-101.

Trummal, V. 1964. Arheoloogilised kaevamised Tartu linnusel. (ENSV ajaloo küsimusi, III. Tartu Riikliku Ülikooli Toimetised, 161.) Tartu.

Trummal, V. 1990. Über die Forschungstand der mittelalterlichen Archäologie in Tartu. - European Symposium for Teachers of Medieval Archaeology, Lund 11-15 June 1990. Lund, 59-64.

Tõnisson, E. \& Lepajõe, J. 1978. Teraviljakasvatusest Eestis 11.-13. sajandil. - Tootmis-teadusliku konverentsi "Taimekasvatussaaduste kvaliteedi tõstmine ja teraviljakasvatuse ajaloo küsimusi”" ettekannete materjale. Tartu, 28-34.

Uudelt, M. 1991. Arheobotaanilised leiud Tartu ja Viljandi vanalinnas. Diplomitöö. Tartu Ülikooli botaanika õppetool.

Valk, H. 1993. About the role of the German castle at the town-genesis process in Estonia: the example of Viljandi. - Castella Maris Baltici, 1. Toim K. Drake. Ekenäs, 219-223.

Valk, H. 1995. Keskaegse Viljandi sünni- ja arenguloost: arheoloogiliste kaevamiste tulemusi 1989-1992. - Õpetatud Eesti Seltsi aastaraamat, 1988-1993. Tartu, 173-174.

Willerding, U. 1978. Die paläo-Ethnobotanik und ihre Stellung im System der Wissenschaften. Berichte der Deutschen Botanischen Gesellschaft, 91, 3-30.

Vissak, R. 1999. The condition of archaeological research in Tartu after 20 years of rescue excavations. - The Medieval Town in the Baltic: Hanseatic History and Archaeology, Proceedings of the First and Second Seminar in Tartu, Estonia. Toim R. Vissak \& A. Mäesalu. Tartu, 33-42.

Vunk, A. 1999. Archaeological surveys and the topography of medieval Pärnu. - The Medieval Town in the Baltic: Hanseatic History and Archaeology. Proceedings of the First and Second Seminar in Tartu, Estonia. Toim R. Vissak \& A. Mäesalu. Tartu, 43-48.

Zeist, W. v., Wasylykova, K. \& Behre, K. E. (toim). 1991. Progress in Old World Palaeoethnobotany. Rotterdam, Balkema. 


\title{
Ülle Sillasoo
}

\section{WHAT WILL BE WITH ARCHAEOBOTANY IN ESTONIA?}

\begin{abstract}
Summary
Archaeobotany is a field little known in Estonia. It is related to archaeological study of plant remains and research into the history of the use of plants. The discipline is not taught at Estonian universities and the specialists who work or have worked in this area could be counted on one hand only. At the same time, the increasing number of archaeological investigations and samples that have been taken for archaeobotanical research refer to a certain necessity and opportunities to go further. Archaeobotanical finds are sources for the history of material culture as far as everyday life of people depends on plants as resources for food, raw material and fuel; next to appeasing material needs plants may also have been used for aesthetical and religious purposes. The lists of plants included in the unpublished reports of archaeological excavations are not to be considered as complete results of archaeobotanical research. Excavations are just one part of the investigation aimed at collecting data on which further research work is based. The major scientific archaeobotanical work that relies on the results collected from excavations analyses and interprets this information. Plants are the objects of archaeobotanical investigation with archaeological matrix being the source, and the purpose of the research is to discover details of everyday life and make generalizations about culture. Thus it is a real interdisciplinary research that cannot be pursued isolated but in collaboration with several specialists, various information and concepts. The same could be said for archaeologists as scientists, particularly for those who work with well-preserved and rich findings from medieval towns, for example. Estonian archaeobotany may be considered as being in crisis, because although there are dedicated specialists to do scientific work, they lack opportunities for that. Medieval archaeological material where a great part of archaeobotanical data come from is scientifically little investigated and used in the research of material culture. The criticism of the author about the situation is the criticism of an unemployed graduated archaeobotanist. She considers it not only her personal problem but as the result of the situation in Estonian archaeology and in Estonian science. As the domestic research centre of medieval town archaeology and material culture is lacking, the author proposes, as a solution, collaboration with foreign colleagues, which at the same time would not exclude improved collaboration between domestic archaeologists, historians and specialists who use natural scientific methods in archaeology.
\end{abstract}

